\title{
Leveraging Energy Efficiency Investments: An Innovative Web-based Benchmarking Tool
}

Filippos Dimitrios Mexis*, Aikaterini Papapostolou, Charikleia Karakosta, Elissaios Sarmas, Diamantis Koutsandreas, Haris Doukas

School of Electrical and Computer Engineering, Decision Support Systems Laboratory, Energy Policy Unit National Technical University of Athens, Athens, 104 31, Greece

\begin{tabular}{l} 
A R T I C L E I N F O \\
\hline Article history: \\
Received: 15 July, 2021 \\
Accepted: 21 August, 2021 \\
Online: 11 October, 2021
\end{tabular}

Keywords:

Energy Efficiency Investments

Sustainable Financing

Integrated benchmarking

\begin{abstract}
A B S T R A C T
Energy Efficiency (EE) plays a key role in decreasing energy consumption at a European level, while it is considered as one of the most cost-efficient means to achieve carbon reduction and reinforce energy sufficiency and security. EE financing is imperative to implement measures that will lead to achieving the desired carbon neutrality and, thus, avert climate change. The majority of EE investments ideas are abandoned during the first stages of investment generation as there is not enough interest by the involved actors to support the maturing of the idea. The present paper aims to boost EE investments by developing a webbased Tool that evaluates project ideas, connecting them with real financing proposals. All the above are being realised through standardised procedures, establishing a concrete typology of five (5) EE sectors, a well-structured risk assessment methodology of five (5) risk categories and (9) risk factors, and a benchmarking procedure that takes into account four (4) broadly used economic criteria and eleven (11) verified sustainability indicators. All the parameters are calculated using the candidate project data and EU official statistics, formulated into four (4) main criteria that are fed into a MultiCriteria Decision Analysis that performs the project's benchmarking. The presented methodology is being practically tested through the development of three (3) innovative Tools (Assess, Agree, Assign) and a stakeholder consultation process with around 200 participants. The Tools filter and benchmark candidate project ideas, based on the standardised benchmarking and the EU Taxonomy sustainability principles, while connecting the most promising project ideas with state-of-the-art financing methods, such as the Green Loans, the Green Bonds and the Energy Efficiency Auctions. By this token, the developed Tools provenly provide added value to the respective stakeholders, offering standardisation in EE project benchmarking and financing, building trust between investors and projects developers.
\end{abstract}

\section{Introduction}

This paper is an extension of work originally presented in 2020 11th International Conference on Information, Intelligence, Systems and Applications (IISA 2020) [1]. The conference was realised virtually in 15-17 July 2021, originally organized in Piraeus, by the University of Piraeus and the University of Thessaly. The conference aims to create a forum for researchers and professionals in all areas of Information, Intelligence, Systems and Applications, while its proceeding are published by the Institute of Electrical and Electronics Engineers (IEEE) and uploaded on the its online platform, IEEEXPLORE.

The attainment of the energy and environmental targets set by the European Union (EU) in view of moving to a carbon-free

*Corresponding Author: Filippos Dimitrios Mexis, E-mails: pmexis@epu.ntua.gr www.astesj.com

https://dx.doi.org/10.25046/aj060526 economy by 2050 requires that more intense policies and measures be put into effect, ensuring that the target trajectory is on track [2]. Out of the available policy measures, the improvement of energy efficiency (EE) can play a key role in this transition, leading to the decrease of energy demand and emissions, as well as bringing about economic and social benefits [3] [4]. For this reason, EE has been recognised as the "first fuel" [5], indicating its essential role and the large-scale effects that it could result in.

Mainstreaming EE is the most feasible solution to maintain increased levels of economic and social activities while being a more sustainable and less energy demanding society [6]. The increase of EE implementation goes together with the upscale of EE investments since a prerequisite for realising EE projects is that the capital needed is secured at their development phase. However, 
according to the current state of play, investments in EE are well below the required level to meet the established long-term targets [7].

Interestingly enough, despite the existence of many EE investments with great prospects at the development phase, only a few of them achieve to get financed; something that has been called as "efficiency paradox" or "energy efficiency gap” [8]. This phenomenon can be ascribed to the transparency gap that EE investments involve [9]. First, there is a shortage of evidence about successfully implemented EE projects, such as about their financial performance and the stakeholders involved within their context. The main factors that halt the financing of EE are the lack of evidence on the performance of such projects, standardised procedures and standards for energy efficiency investments, and the underestimation of its multiple benefits [10]. Moreover, postulating the financial performance of $\mathrm{EE}$ investments is a stochastic task at its nature since it is related to several uncertainties (e.g., energy prices), while their evaluation presents high complexity [11].

To the best of our knowledge, a standardised procedure for this scope does not exist up to date [12]. As a result, project developers do not have the expertise or resources to make a convincing financing case for investors, and, on the other hand, investors face difficulties in identifying the EE projects that merit attention [12]. Likewise, financial institutions, given the high transaction costs for evaluating EE investments with respect to their entailed technical aspects, focus only on the creditworthiness of the borrower for deciding whether they provide a loan or not [13]. Therefore, they may exclude from their portfolios many EE projects of great potential. In order to bridge the transparency gap that exists at the initial phases of EE investments, it is of paramount importance that innovative decision support schemes and standardisation Tools will become available towards providing the required information to the involved actors and key players in EE financing [14], also enabling their connection with each other.

The energy efficiency gap is a great field of interest for energy policy scientists, policymakers and research initiatives. Several efforts have been made to mitigate the energy efficiency gap and stimulate the energy efficiency project implementation in Europe by making use of a variety of different financing and funding methods. In [15], the author have developed a benchmarking framework to encourage EE Investments in South Europe under the financing method of Energy Performance Contracting, while the Energy Efficiency Financing Institutions Group (EEFIG) has evolved the EEFIG Underwriting Toolkit to assist financial institutions in scaling up the deployment of capital into energy efficiency [11]. A different approach is followed in [16] by introducing public-private partnerships to finance EE projects.

In addition, the European Union has funded projects and initiatives so as to research and develop benchmarking and standardisation methods for EE. Some examples are the LAUNCH project [17], which aims to accelerate deal closure and pipeline growth for Sustainable Energy Assets through standardised material and the RenonBill project [18] that provides tools to address the residential sector's energy renovation financing demand and to assess bundle investments. Also, the EEnvest project [19] aims to secure investors' trust in EE actions for existing buildings by developing a combined technical-financial risk evaluation framework focused on the renovation of commercial buildings and the E2DRIVER [20] project is developing a training platform that will boost the collective intelligence of the automotive industry on EE. In the scope of certification, X-tendo [21] and its toolbox introduce features of energy performance certificates to provide public authorities with improved compliance, reliability, usability and convergence of next-generation energy performance assessment and certification.

In this context, this paper proposes a methodological framework that supports, on the one hand, capital providers, i.e., financiers and investors, in finding an attractive project idea that merits attention, giving them access to a pool of project ideas whilst providing a detailed assessment of them. On the other hand, it provides a better understanding of the EE projects' framework to those looking for capital (e.g., project developers), enabling them to acquire the evidence towards performing complete proposals to investors [22].

The presented approach is implemented across three steps, each of which is materialised via a respective standardised Tool. At the first step ("Assess Tool”), the initial filtering and identification of attractive project ideas take place, while also the entailed uncertainty is postulated through the calculation of the total risk of failure of the EE investments under examination. Following, the benchmarking of the EE projects that qualified from the first step is realised ("Agree Tool"), taking into consideration multiple criteria of diverge nature (e.g., economic, energy), thus assessing them from a holistic point of view. In this effort, a multi-criteria approach is employed, resulting in the categorisation of investments. Finally, at the last step ("Assign Tool"), investors are connected to EE project ideas with a detailed description of their characteristics, while the most suitable financing instruments are proposed (e.g., Green Bonds), according to their needs. The pool of available investments is composed of the ones that have passed the first two steps successfully.

Apart from this introductory section, the rest of the paper is organised into five sections. Section 2 analyses the methodological framework of the proposed methodology and Tools' development, while Section 3 describes the materialisation of this methodology along with the methods and data that have been used. Section 4 presents the standardised Tools developed, and, finally, Section 5 concludes the paper and suggests the key points for future research.

\section{Methodological Framework}

The methodology has been structured into five steps, as depicted in the figure below:

Step 1: Identification of the eligible projects.

The proposed methodology aims to benchmark project ideas, which can be considered potential investments at an early elaboration stage. The project ideas should consist of EE measures and interventions that will provenly lead to a decrease in the energy demand of the site implemented. The eligible sectors of activity and type of EE measures should be adequately defined.

Step 2: Review/ Selection of Problem Parameters:

When assessing an EE project, the parameters that should be taken into account are diverse and multivariant, similar to the 
nature of EE measures. The indicators and parameters had to be carefully reviewed and selected so as to include and quantify all aspects of EE measures properly, but also reflect in a standardised way the expected financial performance of these potential investments at the early stage of the project's conceptualisation. State-of-the-art typologies methods have been used in order to produce an integrated and standardised benchmarking.

- Identification of the Eligible Projects

- Review/ Selection of Problem Parameters

- Review/ Selection of Available Methods

- Stakeholders Consultation

-Web-based/ Benchmarking Tool design

Figure 1: Main methodological steps

\section{Step 3: Review/ Selection of Methods}

In this step, a thorough review has taken place in order to run across the most suitable method that can incorporate and weight the selected criteria and benchmark candidate EE projects into predefined classes. Considering all the diverse and distinct factors that EE projects consist of while maintaining versatility, the review was primarily focused on Multi-Criteria Decision Analysis methods (MCDA). Methods such as the PROMETHEE UTADIS and the descendants of the ELECTRE-Tri method, such as the ELECTRE-Tri-B, ELECTRE-Tri-C, ELECTRE-Tri-nC, and ELECTRE-Tri-nB, have been taken into consideration [23].

\section{Step 4: Stakeholders Consultation}

The proposed methodology and the Tools developed are oriented towards EE companies and investors interested in investing in these kinds of projects. In order to properly assess and cover their needs and develop Tools that will provide added value to the EE sector, rigorous stakeholder consultation has been realised. The consultation activities included bilateral contacts, discussions, structured interviews, webinars, and workshops.

The consultation process has been organised into two distinct phases. The first phase took place before developing the respective methodology and Tools and is focused on identifying the design parameters. The second part was released after the initial development of the Tools in order to receive feedback and finetune the benchmarking process and methods. The stakeholder consultation steps are summarised in the following diagram.

The second part of the consultation included demonstrations and testings, which have been conducted in bilateral meetings with EE companies, project developers, and financers interested in sustainable financing. In addition, feedback on the methodology and the developed Tools has been received from 198 stakeholders by the dissemination of dedicated questionnaires.

Step 5: Web-based/ Benchmarking Tool design
The final step consists of the design and the technical development of the benchmarking Tools, which will assist energy efficiency stakeholders, such as investors seeking to finance sustainable projects and developers that design and implement such projects. The Tools will perform a complete series of actions corresponding to the value-chain of energy efficiency financing. First, the risks and maturity of the inserted investment ideas together with their EU Taxonomy compliance are being evaluated, and then the projects that pass the pre-evaluation are classified into predetermined categories to identify the Triple-A ones. Finally, the last step of Tools matches the investments with state-of-the-art green financing schemes.

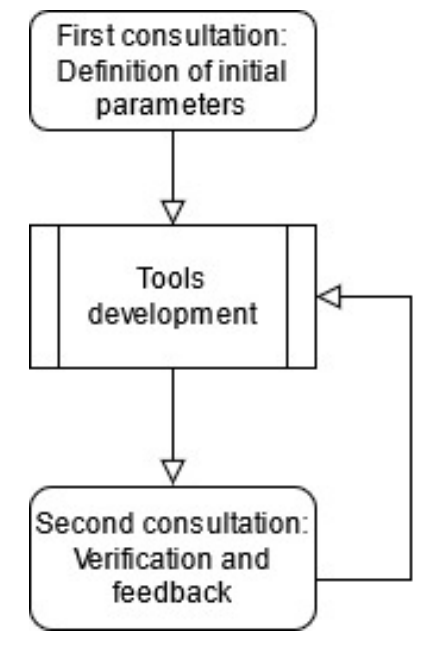

Figure 2: Stakeholder consolation steps

The Tools have been developed in Python 3.0 programming language, taking into advantage the versatility and power framework that it provides. In addition, the Python Django framework has been used to combine the individual scripts for the risk assessment, MCDA method, and criteria calculations into an integrated web-based environment with easy to use front-end and back-end functionalities. The back-end service utilises the SQLite database, while the app is hosted on the National Technical University of Athens' servers.

The Tools' design, functionalities, input-output data and the respective procedures, along with flowcharts, are presented and analysed in depth in Section 4: Web-based Benchmarking Toolbox.

\section{Methods and Data}

The proposed methodology is based on the actual needs of the EE financing sector, while the design parameters and requirements of the problem have been identified and verified through stakeholder consultation. All the respective processes, such as the identification, review, stakeholder consultation and development, have been realised within H2020 Triple-A project activities and are of vital importance for the assessment and mainstreaming of EE investments. For example, the ELECTRE Tri multi-criteria analysis method has been utilised for the necessary classification of the investments, the project risk elicitation methodology has been crucial for the identification of risky projects which could be immediately rejected from the Triple-A Assess Tool, and the Key Performance Indicators (KPIs) serve as the most suitable criteria 
concerning the financial prosperity of the investments. Therefore, before presenting the Triple-A Tools step-by-step, it is essential to deliver the underlying methodological basis, referring to the tools' components.

\subsection{Identification of the eligible projects.}

The potential investments in EE measures covered by the presented methodology should be pertaining to the following five (5) sectors (i) Buildings, (ii) Manufacturing, (iii) Transportation, (iv) District energy networks, and (v) Outdoor lighting.

The project sectors have been identified in order to form a consistent typology that will include the majority of EE measures in such a way as to simplify the user experience of the developed Tools and batch them in a manner that will benefit the calculations of the respective benchmarking. The eight identified sectors are analysed in the following paragraphs:

- Building sector: Building sector projects ideas include any renovation compliant with the energy performance standards set in the applicable building regulations for major renovations transposing the Energy Performance of Buildings Directive (EPBD) or renovations that achieve energy savings of at least $30 \%$ in comparison to the baseline performance of the building before the renovation. The baseline performance and predicted improvement shall be based on a specialised building survey and be validated by an accredited energy auditor. Individual renovation measures and installation of renewables on-site that contribute to climate change mitigation by reducing GHG emissions and professional, scientific and technical activities necessary to support and validate buildings' renovation are also included in the Building sector [24]. Also, the construction of new buildings can be included if they meet at least the national requirements for nZEB and have a level of energy performance equivalent to the EPC rating of $\mathrm{B}$ (or above).

- Manufacturing sector: Under the Manufacturing sector are included projects of $\mathrm{EE}$ measures in industries in order to manufacture products with high EE, compared to relevant products already in the market, of manufacture products, key components and machinery that are essential for implementing projects that achieve high EE. More generally, any intervention in industries that aim to reduce energy losses and to improve the energy performance of equipment, machinery or install renewable energy systems can be included. Equally, improvement of existing industrial production lines and processes to achieve significant improvement of their EE and reduction of GHG emissions per unit of product are covered.

- Transportation sector: The Transportation sector includes measures in public transport vehicles, which can achieve substantial GHG emission reduction in terms of CO2e emissions per passenger- kilometre $(\mathrm{gCO} 2 \mathrm{e} / \mathrm{km})$. The potential project should be referred to zero direct emissions land transport solutions, such as light rail transit, metro, tram, trolleybus, bus and rail, or fleets with direct emissions below $50 \mathrm{gCO}_{2} \mathrm{e} / \mathrm{pkm}$ until 2025 (non-eligible thereafter). Additionally, projects to finance the replacement of corporate fleet with new, more efficient passenger cars are included. The vehicles can be light commercial vehicles and category $\mathrm{L}$ vehicles (2- and 3-wheel vehicles and quadricycles).

- District Energy Networks: As District Energy Networks are considered the construction projects, retrofit, expansion and operation of pipelines and associated infrastructure for distributing heating and cooling. For a project to be eligible, the system should meet the definition of efficient district heat/cool systems in the EU Energy Efficiency Directive and EIB energy lending policy regarding phasing out fossil fuels ("Supporting the energy transformation"). In detail, "efficient district heating and cooling" is defined as a district heating or cooling system using at least 50\% renewable energy, 50\% waste heat, $75 \%$ cogenerated heat or $50 \%$ of a combination of such energy and heat.

- Outdoor lighting: The Outdoor lightning sector includes any project focused on the renovation or renovation and expansion of existing outdoor lighting installation (e.g. street lighting, lighting of public squares) that lead to a high EE performance. All projects should foresee an appropriate control and measurement system.

\subsection{Review/Selection of Problem Parameters}

The problem parameters are the key elements that form the criteria used in the methodology. The criteria, in turn, are defined and quantified by relevant indicators that can reflect EE project characteristics. In the presented methodology, the indicators for the benchmarking include data regarding the EU Taxonomy compliance of projects, risk estimations per country, sector, economic and financial KPIs based on project's characteristics, and the multi-benefits of projects as depicted by the potential contribution of EE measured by the Sustainable Development Goals. The typology and formation of the criteria have been inspired by the Final Standardised Tools Deliverable [25] published within the context of the Triple-A H2020 project. In the following paragraphs, each indicator type will be presented and explained.

- EU Taxonomy compliance: The methodology has pointed out the EU Taxonomy Technical screening criteria for each the identified project's sector. The criteria include thresholds regarding the technical characteristics of the proposed EE projects, which vary from one sector and type of activity to another. The technical screening criteria of the EU Taxonomy have been used to all the sectors, except the Outdoor Lighting sector, for which a dedicated set of criteria has been used, based on the outcomes of the PREMIUM LIGHT PRO project [26].

- Risk Assessment: The risk assessment of the potential investments in EE focuses on estimating in a qualitative and quantitative approach the total investment risk caused by a variety of factors. These factors are linked to the nature and principles of EE or country and sector individual characteristics [27]. The factors have been adequately identified and grouped into five (5) distinct risk categories. The categorisation aims to group the identified risk factors based on their conceptual characteristics and to facilitate the quantification procedure of the investment's risk. The aggregation of the risk parameters into a total investment risk 
has been realised by applying a weighted average formula, as analysed in Section 3. The risk assessment methodology has been inspired by the Final Report on Risks of Energy Efficiency Financing and Mitigation Strategies Typology published within the context of the Triple-A H2020 project [28].

- Economic KPIs: The economic parameters could not be missing from a benchmarking methodology of potential investments. A selection of classic financial indicators, broadly used by investors, has been carried out, while the calculation methods have been parameterised to fit the cashflows and particularities of EE measures.

- The indicator's calculation has been based on EU Directives and Regulations on Cost-Benefit Analysis of Investment Projects, while data from EU official statistics have been used to provide a standardised, unbiased result. The indicators included in the benchmarking procedure are the Net Present Value (NPV), the Discounted Payback Period, the Internal Rate of Return (IRR), and the Cost-Effectiveness (or Avoidance Cost) [25].

- Sustainable Development Goals: An aggregated indicator has been included as a criterion in the benchmarking methodology, reflecting the necessity to improve EE in the case study countries and the identified sectors. The indicators used are official Eurostat statistics linked with the progress of the UN's Sustainable Development Goals. These indicators reflect the current situation of EE per country and sector, the situation regarding energy poverty, environmental pollution and greenhouse gas emissions, and energy security sufficiency. Overall, a total of 11 sustainability indicators have been included, linked with the multi-benefits of EE and aggregated into a single criterion.

\subsection{Review/Selection of available methods}

The review and selection of the most appropriate method is a crucial element enabling the benchmarking of the EE investment ideas to be performed in an affluent and efficient way. The problem parameters and requirements, such as the benchmarking of EE project ideas, in predefined classes based on several criteria, emphasised the need for a multi-criteria approach.

ELECTRE Tri was considered the most appropriate methodology to address the problem, as it accumulates key advantages that match the needs of the problem in question. The determinant factor that led to select the ELECTRE-Tri Multiple Criteria Decision Analysis as the benchmarking method is that it allows the classification of the candidate projects into predefined categories (alternatives) by constructing outranking relations and comparing each alternative to a limit [29].

Also, one of the strong points is that ELECTRE-TRI handles both qualitative and quantitative data, meaning that it can deal with the imperfect nature of knowledge [30]. It is a multi-criteria decision-making method which is mainly utilised for classification problems, providing labelling of the alternatives based on a set of conflicting and non-overlapping criteria.

Not to mention the discrimination thresholds that the selected method incorporates, which eliminate the serious drawbacks of imprecision, ill-determination, and uncertainty that can undergo with the data available and used. The theoretical background, steps and processes performed in the ELECTRE Tri method are thoroughly presented in the relevant bibliography in [31], [32]

\subsection{Calculation of the EE investments risk}

In the context of the proposed methodology, an important pillar is calculating the investment's total risk, which was determined by combining both a qualitative and a quantitative approach. The major factors that affect the security of the implementation of investment that mainly consist of EE measures have been classified into the following five categories. Each risk category consists of risk factors that are estimated based on formulas or linguistic values, according to their nature.

- Financial risk is related to the creditworthiness of the applicant for the loan/financing. It consists of the risk factor "creditworthiness of the borrower". This factor indicates the financial capacity of the borrower to pay off his debt. It is considered a critical factor from the perspective of a financing institution or bank when considering giving a loan [33,34]. The risk factor is qualitative, and it is estimated by assigning linguistic values out of the scale ("Low", "Medium”, "High", "Unknown") for evaluating the creditworthiness of the applicant for the loan.

- Behavioural risk is related to the rebound effect that may exist in the context of the inspected EE investment. It consists of the risk factor "rebound effect", which describes a specific behavioural bias in sites that have been implemented EE measures. This bias affects the end-user, and it usually emerges when the implementation of an EE project leads to lower costs for energy services combined with an increase in the demand for such services. It is a qualitative risk factor, and it is being quantified by assigning linguistic values out of the scale ("Insignificant “, "Low “, "Medium”, "High“, "Very High") to each type of project based on literature review and questions replied by the applicant of the project idea, as inspired by the Industrial Energy Accelerator project by UNIDO [35] .

- $\quad$ Energy Market \& Regulatory risk consists of factors related to the country's energy prices and energy taxes volatility (and in which the investment will be implemented) and the requests for issuing work permits that may exist in the context of the inspected project. Energy prices and taxes volatility is associated with the price risk in EE investments, and it is a quantitative factor calculated based on the coefficient of variation (CV) of monthly values of Consumer Price Index (CPI) for the last fifteen years (01/2005-12/2019), as reported by OECD. The risk factor "request for issuing project permits" signifies the legislative complexity for the completion of a project and consists of a qualitative analysis considering the amount and type of project permits needed for the implementation of the project.

- Economic risk is differentiated from financial risk, and it is related to the country's economic environment that the investment takes place. The risk factor that facilitates the quantification of this project category is the "weak economic environment", which is connected to, among others, the country's interest rates, inflation, availability of finance, etc. [36]. It is a qualitative factor, quantified by the credit ratings 
provided by Standard \& Poor's (S\&Ps) for the case-study countries.

- $\quad$ Technological, Planning and Operational risk is related to the technical complexity, the initial savings assessment, the implemented equipment, the project design, and the Operation \& Maintenance of the inspected project. In more detail, the risk factors that are included in this Risk Category, are qualitative and they are quantified by assigning linguistic values out of the scale ("Insignificant", "Medium", "Very high") to each type of project based on questions answered by the applicant of the project. Specifically, the "Low quality of initial savings assessment” risk factor considers how the energy savings assessment and the baseline definition have been conducted. The "Implementation of low-quality equipment or poor project design" considers the existence of proof about the quality of the equipment to be installed, the experience of the team for planning and implementing the project and who conducts the technical implementation of the project. The "Inadequate Operation \& Maintainance" considers the experience of the end-user in using and operating the proposed equipment, the existence of a maintenance plan, product warranties and Measurement \& Verification protocols and standards.

Following the determination of the risk factors' values, the risk categories' values are then calculated by averaging the values of the risk factors of which each category is composed. The risk is being calculated by deploying the method of the weighted average

The total project risk value is the weighted arithmetic mean of the risk categories' values and is calculated as follows:

$$
\begin{gathered}
\text { Project risk value }=\sum_{i=1}^{n} w_{i} \times R_{i} \\
w_{i}: i=1, \ldots, 5 \text { are each risk category's weight } \\
R_{i}: i=1, \ldots, 5 \text { are each risk category's value }
\end{gathered}
$$

The weights used in the equation emerge from the stakeholder consultation process that has been realised within the Triple-A project's activities. The weights values have been calculated through the respective answers in linguistic variable questions regarding the investors' preferences and their perception of energy efficiency projects' risk, and project developers' risk prioritisation according to the estimated impact on the EE projects implementation.

\subsection{Final formation of the KPIs serving as classification criteria}

The application of the ELECTRE Tri method, which was selected to follow through with the problem in question, is based on the elicitation of a series of criteria. These criteria emerge from the identified project parameters, as presented in Paragraph 3.2, and should follow the principles and restrictions implied by the ELECTRE-Tri methodological background. The final formation should produce non-overlapping criteria and which must affect directly the evaluation of the examined alternatives (EE investments). The selected criteria reflect the economic prosperity, the risk and the sustainability of the potential investment, based on specific KPIs.

The first two criteria consist of economic KPIs broadly used in the classic benchmarking of potential investments in the financing sector. The KPIs are calculated taking into account the expected economic savings of the potential EE investments, while the KPIs parameters are based on the EU Directives and Regulations on Cost-Benefit Analysis of Investment Projects or reflected directly from EU official statistics to provide standardised unbiased results. The origin of the applied KPIs aspires to build confidence among investors and facilitate financing bodies and EE funds to detect and finance projects that meet the necessary criteria rapidly.

The first criterion is the economic indicator of CostEffectiveness. Cost-Effectiveness refers to the ratio of dis-counted benefits over the discounted costs. In its simplest form is a measure of whether an investment's benefits exceed its costs [37]. In the proposed methodology, the Cost-Effectiveness is calculated based on the project cost per kWh saved

The second criterion is also an economic indicator selected by the respective stakeholder of each potential investment. The selection can vary between the KPIs listed below:

- $\quad$ Net Present Value (NPV), reflecting the risk and cashflows discount by quantising it through the discount rate, the profitability of the investment by involving in the calculations the yearly income, the operational costs and the initial investment [38].

- Discount Payback Period, which quantifies the number of years necessary to recover the investment's budget while accounting for the time value of money [39].

- Internal Rate of Return (IRR) is a rate of return used in capital budgeting to measure and compare the profitability of investments.

- Cost-Effectiveness. Which refers to the ratio of dis-counted benefits over the discounted costs. In its simplest form is a measure of whether an investment's benefits exceed its costs [37]. In the proposed methodology, Cost-Effectiveness is calculated based on the project cost per kWh saved

The third criterion comprises the aggregated total investment risk, reflecting the likelihood of the unwanted case that the potential investment will not achieve the proposed savings in energy and thus fail to deliver the expected economic benefits. The aggregated total risk is calculated through the procedure described in detail in Paragraph 3.4.

The fourth criterion refers to the sustainability aspects of the proposed investment. Expect the financial and risk criteria, sustainability criteria are considered essential and have been incorporated into the methodology, as EE investments provide multi-benefits in social and environmental aspects, except energy savings. For example, they contribute to environmental and social factors while reducing energy consumption, leading to lower GHG emissions, improving comfort in living spaces, and industry productivity.

The sustainability criterion for the proposed methodology has been based on the United Nations' Sustainable Development Goals indicators have been selected based on quantitative analysis, as recorded by Eurostat's statistical indicators. These indicators reflect the current situation of EE, energy poverty, and environmental pollution. The identified indicators are directly linked with the United Nations' Sustainable Development Goals (SDG) Agenda [40], mainly to those related to the energy sector and environmental protection. The criterion emerges from the aggregation of statistical data per country or per country and sector, depending on the dataset's nature. 
The utilised SDG factors that were aggregated in order to construct the SDG criterion for the ELECTRE Tri method are presented in Table 1 Selected SDG indicators.

Table 1: Selected SDG indicators.

\begin{tabular}{|c|c|}
\hline Name & Criterion \\
\hline Arrears on utility bills & $\begin{array}{l}\text { It reflects the share of (sub)population (\%) } \\
\text { having arrears on utility bills, based on the } \\
\text { question "In the last twelve months, has the } \\
\text { household been in arrears, i.e. has been } \\
\text { unable to pay on time due to financial } \\
\text { difficulties for utility bills (heating, } \\
\text { electricity, gas, water, etc.) for the main } \\
\text { dwelling?" }\end{array}$ \\
\hline $\begin{array}{l}\text { Total population living in a } \\
\text { dwelling with a leaking roof, } \\
\text { damp walls, floors or } \\
\text { foundation, or rot in window } \\
\text { frames or floor }\end{array}$ & $\begin{array}{l}\text { It indicates the share (\%) of the population } \\
\text { experiencing at least one of the following } \\
\text { basic deficits in their housing condition: a } \\
\text { leaking roof, damp walls, floors or } \\
\text { foundation, or rot in window frames or floor. }\end{array}$ \\
\hline $\begin{array}{l}\text { Population unable to keep } \\
\text { home adequately warm by } \\
\text { poverty status }\end{array}$ & $\begin{array}{l}\text { It indicates the share (\%) of the population, } \\
\text { who are unable to keep home adequately } \\
\text { warm. Data for this indicator are being } \\
\text { collected as part of the EU Statistics on } \\
\text { Income and Living Conditions (EU-SILC) to } \\
\text { monitor the development of poverty and } \\
\text { social inclusion in the EU. }\end{array}$ \\
\hline Primary energy consumption & $\begin{array}{l}\text { It quantifies the Gross Inland Consumption } \\
\text { in toe, excluding all non-energy use of } \\
\text { energy carriers (e.g. natural gas used not for } \\
\text { combustion but for producing chemicals). }\end{array}$ \\
\hline Energy import dependency & $\begin{array}{l}\text { The criterion shows the share (\%) of the total } \\
\text { energy needs of a country met by imports } \\
\text { from other countries. It is calculated as net } \\
\text { imports divided by the gross available energy }\end{array}$ \\
\hline $\begin{array}{l}\text { Final energy consumption in } \\
\text { the industry sector }\end{array}$ & $\begin{array}{l}\text { It includes all the energy supplied to the } \\
\text { industry sector in toe; excluding deliveries to } \\
\text { the energy transformation sector and the } \\
\text { energy industries themselves). }\end{array}$ \\
\hline $\begin{array}{l}\text { Final energy consumption in } \\
\text { the transportation sector }\end{array}$ & $\begin{array}{l}\text { It measures the energy consumption of the } \\
\text { transportation sector in toe, excluding } \\
\text { deliveries to the energy transformation sector } \\
\text { and the energy industries themselves. }\end{array}$ \\
\hline $\begin{array}{l}\text { Final energy consumption in } \\
\text { other sectors or commercial } \\
\text { and public services }\end{array}$ & $\begin{array}{l}\text { It indicates the energy supplied to non- } \\
\text { categorised sectors, commercial and public } \\
\text { services in toe. }\end{array}$ \\
\hline $\begin{array}{l}\text { Final energy consumption in } \\
\text { households per capita }\end{array}$ & $\begin{array}{l}\text { The indicator measures how much electricity } \\
\text { and heat every citizen consumes at home } \\
\text { (kgoe/capita), excluding energy used for } \\
\text { transportation. Since the indicator refers to } \\
\text { final energy consumption, only energy used } \\
\text { by end consumers is considered. }\end{array}$ \\
\hline $\begin{array}{l}\text { GHG emissions from energy } \\
\text { consumption }\end{array}$ & $\begin{array}{l}\text { The data are based on measures of the } \\
\text { European Environmental Energy Agency } \\
\text { and represent the GHG emissions caused by } \\
\text { the energy sector in ktn } \mathrm{CO}_{2 \text {-eq. }}\end{array}$ \\
\hline $\begin{array}{l}\text { GHG emissions from the } \\
\text { industrial sector }\end{array}$ & $\begin{array}{l}\text { Similar to } \mathrm{C}_{10} \text {, the } \mathrm{C}_{11} \text { criterion contains the } \\
\text { GHG emissions (in ktn } \mathrm{CO}_{2 \text {-eq }} \text { ) caused by the } \\
\text { industrial sector, as reported by the European } \\
\text { Environmental Energy Agency. }\end{array}$ \\
\hline
\end{tabular}

The four criteria mentioned above are calculated automatically by the Triple-A Web-based Benchmarking Toolbox presented in Section 4. The calculation is being performed in the back-end of the respective Tool, while the user only needs to provide the data required for the calculations and reply to the requested questions. As described thoroughly in Paragraph 3.7, the four criteria feed a MultiCriteria Decision Analysis Method, which in turn performs the final benchmarking of the Web-based Benhcmaking Toolbox.

\section{Web-based Benchmarking Toolbox}

The methodology, typology, and expected results analysed in the previous paragraphs have come into existence by the implementation of web-based Tools [1]. The Tools form part of an integrated Toolbox, namely the Triple-A Toolbox, which has been implemented in the Python 3.0 programming language.

The Toolbox aims to perform an initial filtering of the EE project ideas, benchmark them into predefined classes, and connect them with investors via concrete financing methods. The examined projects, along with their attributes (project country, project sector, aggregated project risk etc.), are saved into a database in order to be identifiable and open for financing requests.

The Toolbox consists of three distinct Tools, namely the Assess Tool, the Agree Tool and the Assign Tool. The project architecture is designed in a way that each Tool can be used separately, thus offering interoperability among the different modules. The steps for each module of the Triple-A Toolbox are presented in Figure 3.

\begin{tabular}{|l|l|l|}
$\begin{array}{l}\text {-Initial project } \\
\text { details } \\
\text { - Overall } \\
\text { Assessment of } \\
\text { main risks and } \\
\text { maturity } \\
\text {-Go - NoGo } \\
\text { process }\end{array}$ & $\begin{array}{l}\text { Calculation of } \\
\text { projects' KPIs } \\
\text {-Labelling of } \\
\text { projects into } \\
\text { predefined } \\
\text { classes }\end{array}$ \\
$\begin{array}{l}\text { Matchmaking of } \\
\text { investment ideas } \\
\text { with available } \\
\text { financing } \\
\text { schemes } \\
\text { - Interaction } \\
\text { between investors } \\
\text { and project } \\
\text { developers }\end{array}$ \\
\hline
\end{tabular}

Figure 3: Web-based Tools functionalities

\subsection{Assess Tool}

The Assess Tool aims to perform initial filtering and screening of the EE project ideas. The main idea of the Assess Tool is the overall assessment of the main risks and the maturity, the candidate EE investments, and their EU Taxonomy compliance. To evaluate the risk of each EE investment, its main characteristics are considered, such as the country of implementation and the technology implemented within its context. On the one hand, the considered risks are related to the region where the project is implemented, the proposed technologies that are used, and the project management. On the other hand, the maturity of the investments is related to their readiness for implementation. In this respect, several key factors that could possibly affect the project's success and its access to sustainable financing have been considered (e.g., risk level, size of the investment, type of EE projects, EE measures eligible, EU Taxonomy compliance etc.), serving as eligibility criteria, aiming to assure the security and trust of the potential investments, which is a necessary action in order to proceed to further analysis.

The flowchart of the Assess Tool methodology is presented in Figure 4: 


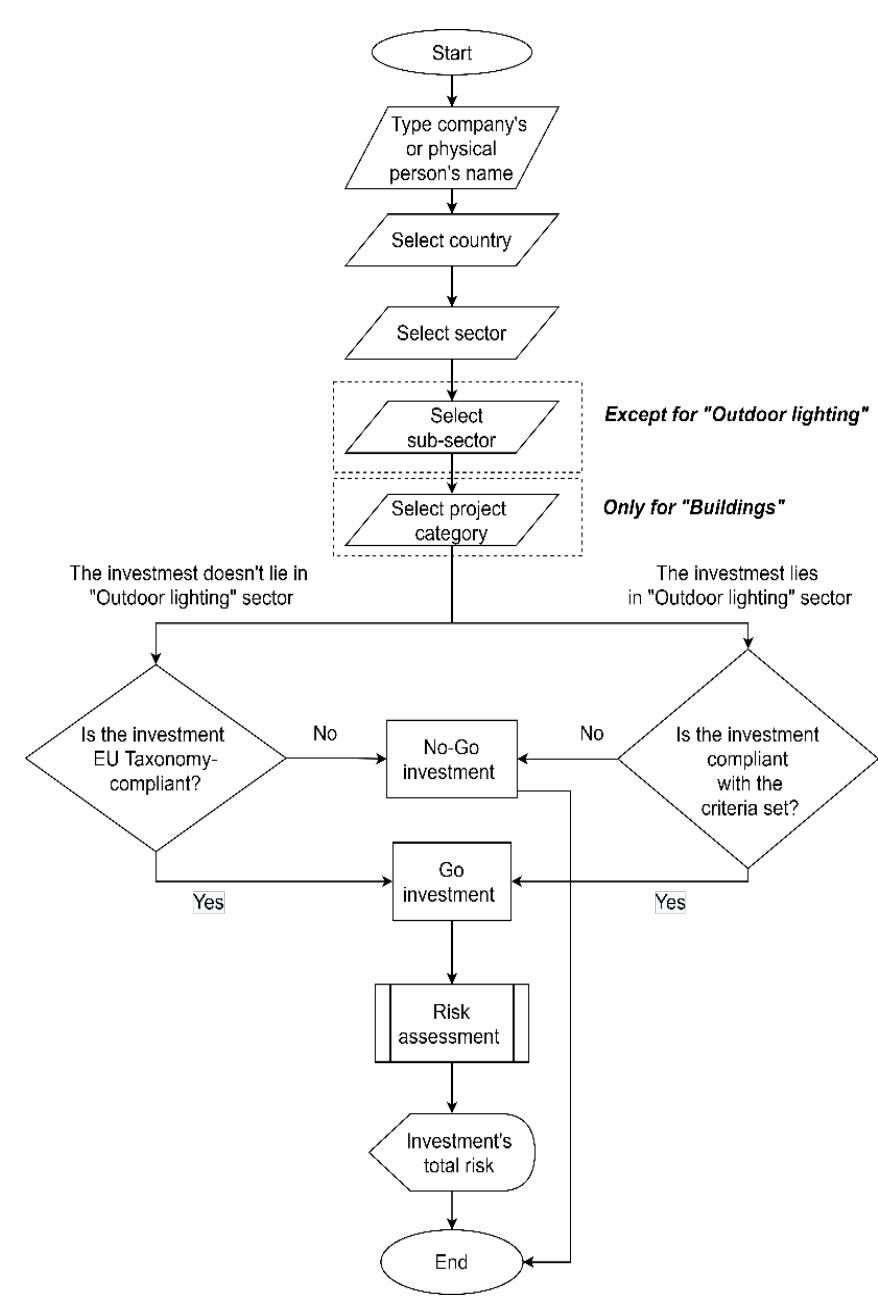

Figure 4: Assess Tool Flowchart

From the user's perspective, this Tool includes the following steps:

Step 1: Inserting the basic information of the candidate EE project (Company's or Physical person's name, country, sector).

Step 2: Selecting the project's subsector (except for the "Outdoor Lighting” sector). The project sectors and subsectors are presented in Table 2.

Step 3: Selecting the project category (Only for the building's sector; Table 4). In case that the investment concerns a building, select the project category, as presented in Table 3.

Table 2: Assess Tool Sectors

\begin{tabular}{|l|l|l|}
\hline A/A & Sectors & Sub-sectors \\
\hline \multirow{3}{*}{$\mathrm{S}_{1}$} & Buildings & Residential \\
\cline { 3 - 3 } & & Non-Residential \\
\hline \multirow{5}{*}{$\mathrm{S}_{2}$} & \multirow{2}{*}{ Manufacturing } & Hydrogen \\
& & Iron and Steel \\
& & Aluminum \\
\cline { 3 - 3 } & & Cement \\
\cline { 3 - 3 } & & Low carbon technologies \\
\cline { 3 - 3 } & & Fertilisers and Nitrogen \\
\cline { 3 - 3 } & & Other organic basic chemicals \\
\cline { 3 - 3 } & & Other inorganic basic chemicals \\
\hline $\mathrm{S}_{3}$ & Transportation & Public Transport \\
\hline
\end{tabular}

www.astesj.com

\begin{tabular}{|l|l|l|}
\hline & & $\begin{array}{l}\text { Passenger cars and light } \\
\text { commercial vehicles }\end{array}$ \\
\hline \multirow{3}{*}{$\mathrm{S}_{4}$} & $\begin{array}{l}\text { District Energy } \\
\text { Networks }\end{array}$ & $\begin{array}{l}\text { District Heating / Cooling } \\
\text { Distribution }\end{array}$ \\
\cline { 3 - 4 } & & $\begin{array}{l}\text { Installation and operation of } \\
\text { electric heat pumps }\end{array}$ \\
\cline { 3 - 4 } & & $\begin{array}{l}\text { Cogeneration of Heating / } \\
\text { Cooling and Power }\end{array}$ \\
\cline { 3 - 4 } & & Production of Heating / Cooling \\
\hline $\mathrm{S}_{5}$ & Outdoor Lighting & - \\
\hline
\end{tabular}

Table 3: Assess Tool project categories.

\begin{tabular}{|l|l|l|}
\hline Sectors & A/A & Project categories \\
\hline \multirow{4}{*}{ Buildings } & $\mathrm{P}_{1}$ & Building envelope retrofits \\
\cline { 2 - 3 } & $\mathrm{P}_{2}$ & HVAC\&R retrofits \\
\cline { 2 - 3 } & $\mathrm{P}_{3}$ & Lighting appliances' retrofits \\
\cline { 2 - 3 } & $\mathrm{P}_{4}$ & Automatic control retrofits \\
\cline { 2 - 3 } & $\mathrm{P}_{5}$ & RES installations \\
\cline { 2 - 3 } & $\mathrm{P}_{6}$ & $\begin{array}{l}\text { Construction of new } \\
\text { buildings }\end{array}$ \\
\hline Manufacturing & $\mathrm{P}_{7}$ & $\begin{array}{l}\text { Manufacturing-specific } \\
\text { retrofits }\end{array}$ \\
\hline Transportation & $\mathrm{P}_{8}$ & Purchase of new vehicles \\
\hline $\begin{array}{l}\text { District Energy } \\
\text { Networks }\end{array}$ & $\mathrm{P}_{9}$ & $\begin{array}{l}\text { District Energy Networks } \\
\text { retrofits/ expansion }\end{array}$ \\
\hline Outdoor Lighting & $\mathrm{P}_{10}$ & Outdoor lighting retrofits \\
\hline
\end{tabular}

Step 4: After having imported all the project-specific information, select whether the investment is EU taxonomy eligible. Depending on the project sector, as well as the additional information is given (Project Type, Project Category, etc.), an EU taxonomy list appears, including the thresholds that need to be met by the investment and some explanations on the requirements, such as the metrics of each threshold. Then, the user should carefully check if the investment fulfils all the thresholds. In case that all the requirements are met, then the Yes checkbox should be selected, stating that the investment is taxonomy compliant. Finally, the user must fill in a checklist with taxonomy criteria, according to whether the investment is compliant with the criteria set in each case or not.

Step 5: Message notification to inform the user whether the project is Go or No-Go. If the answer to the EU Taxonomy compliance questions sets a project as No-Go, the user is notified immediately, without being able to complete the remaining steps of the Tool.

Step 6: Answer a series of project-specific questions, which are taken into consideration for the aggregated investment risk calculation.

Step 7: Calculation of the project's aggregated risk, according to the methodology described in Paragraph 3.4.

Step 8: Analytic presentation of the project's risk calculations, including the calculation for each distinct risk category, as described in Paragraph 3.4 and the total calculated risk of the investment.

\subsection{Agree Tool}

The Agree Tool implements the second pillar of the proposed benchmarking scheme for the EE project identification and labelling. The Agree Tool can only be applied to EE project ideas 
that have successfully passed the Assess Tool and have been identified as "Go" projects. The Tool supports and facilitates the identification of the so-called Triple-A investments [12], e.g. the investments that have a high performance in the selected KPIs, as described in Paragraph 3.5. In other words, Triple-A EE investments are defined as the ones with extremely strong potential to meet their energy-saving targets, already from their conceptual phase. The candidate projects that are inserted into the Agree Tool are classified into one of the following categories: "Triple-A", "Reserved", or "Rejected", according to their performance on the evaluation criteria.

The flowchart of the Triple-A Agree Tool methodology is presented in Figure 5.

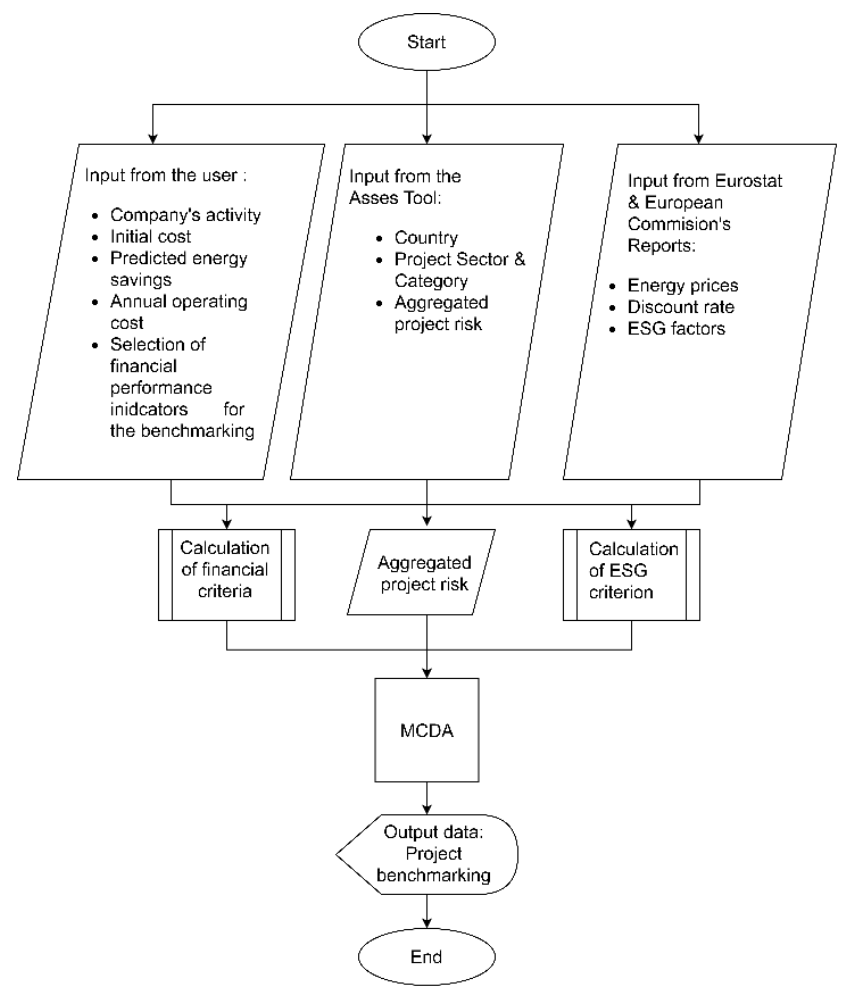

Figure 5: Agree Tool flow chart.

The steps for the Agree Tool from the user's (investor, banker, financer) point of view are described in detail as follows:

Step 1: Definition of project country and project sector in order to set the ELECTRE Tri algorithm's thresholds to the customised values.

Step 2: Select the criteria which will be used for the evaluation of the project and also insert the required input for the calculation of the criteria. The ELECTRE Tri algorithm is applied on the basis of 4 evaluation criteria, as described in Paragraph 3.5. There are two financial criteria (K1 \& K2) combined with one aggregated risk criterion (K3) and one SDG criterion (K4). The criteria of ELECTRE Tri must comply with the restriction of consistency. Therefore, two financial KPIs should be applied to the algorithm. The aggregated risk criterion is fed to the model from the Assess Tool's risk calculation process. Finally, the SDG criterion stems from the methodology discussed in Paragraph 3.5.

Step 3: Weight adjustment of the ELECTRE Tri criteria according to the importance of each factor and the user's preferences. The established weights reflect the effect of each criterion on the final benchmarking. Extreme weight values ( $0 \%$ or $100 \%)$ are rarely assigned to a criterion. At the same time, the sum of all criterion weights should be $100 \%$. The Agree Tool supports default values for weights which can be easily changed by the user from the Tool's interface. The criteria thresholds of the benchmarking classes have been set according to outcomes of similar web-based Tools and databases that accumulate data and knowledge from implemented EE projects, such as the DEEP platform [41], as well as from input provided by experts via the stakeholder consultation. Until March 2021, a number of almost 100 users (project partners, Triple-A project Advisory Board Members and external stakeholders) have been signed up and tested the developed Tools, providing valuable feedback. In addition, the Triple-A Tools have been tested with real projects that have been collected in an EE project pipeline within the Triple-A project activities.

Step 4: After the execution of the multi-criteria algorithm analysis, the candidate EE project is classified into one of the predefined categories: Triple-A, Reserved, and Rejected. The three categories are explained in the paragraphs below:

Triple-A Projects: This category includes projects which could be considered as the best investment opportunities and, thus, merit attention by the funding organisations. These are investments that demonstrate extremely strong potential to meet their energy-saving targets, from their primitive phase, when they are still considered as project fiches from the funding institutes. The above characterisation comes in accordance with the definition of the respective Triple-A investment grade, which refers to investments with a strong capacity to fulfil their financial commitments by achieving the expected performance targets.

Reserved Projects: This category includes a series of projects which are profitable, but they do not guarantee that they will fulfil the predefined performance targets. Such projects have achieved a good but not outstanding performance according to the evaluation criteria. Even though they have not managed to achieve the top score in the evaluation methods, they are capable of repaying the initial capital invested and of contributing significantly to the energy savings.

Rejected Projects: This category includes projects which have a poor total performance according to the evaluation criteria. Their risk is higher than the predefined threshold, and they seem incapable of recovering the total investment. Also, projects which were labelled as "No-Go" during the Triple-A Assess phase are also characterised as Rejected.

\subsection{Assign Tool}

The Assign Tool implements the final step of the integrated methodological framework. The main functionality of this Tool is the matchmaking of investment ideas, which have successfully passed the Assess and Agree tools, with a list of potential financing schemes. Thus, it aspires to support all involved parties to achieve project delivery, such as contracts, underwriting procedures, etc.

The Assign Tool includes numerous user interfaces in order to facilitate all beneficiaries and EE financing instruments. The platform's main target groups are, on the one hand, financing bodies and, on the other hand, companies and project developers. From the aspect of financing bodies, commercial or green investment banks are included, as well as investment funds, developers and managers of financial products, Unit Investment Trust and several types of financers that target financing Triple-A 
opportunities to include in their portfolio. From the aspect of project developers, the Tool is oriented towards EE companies, credit professionals, ESCOs, construction companies and management investment companies that try to attract financing in order to implement their projects.

The flowchart of the Assign Tool methodology is presented in Figure 6.

The Assign Tool provides three different types of financing schemes, aiming to be as flexible as possible and to provide several options for both financing bodies and project developers. The three supported types of financing are (a) Green Loans and Mortgages and (b) Green Bonds, and (c) Energy Efficiency Auctions.

Loans are one of the most traditional financing mechanisms, although their characteristics may vary significantly for different financing cases. During the last decades, financing institutes have prioritised environmental issues and objectives, and Green financing products have emerged as a new trend. [42]. The developed Tool has classified the financing cases to Green Loans and Green Mortgages. The need for such classification has emerged because of the popularity of such financial products, even though mortgages are a form of a loan.

The Assign Tool supports the procedure of financing proposals between investors and project developers. Investors are enabled to send financing proposals for projects, having the flexibility to set the preferred loan parameters. Any type of financing proposal is acceptable, e.g., investors are not obliged to cover the total cost of a project. They could partially finance the project and select the preferred percentage of leverage. Project developers can assess the proposal and accept or reject it by using their personalised interface of the Tool.

The second type of financing, which is supported by the TripleA Assign Tool is Green Bonds. A bond is a type of investment that represents a loan between a borrower and a lender, being considered a debt investment. Green Bonds are any type of bond instrument where the proceeds will be exclusively applied to finance or re-finance, partly or fully, new, or existing eligible Green Projects [43]. The Assign Tool introduces a new methodological approach, enabling an investor to come across companies and project developers to aggregate their projects into a portfolio. EE projects are often small and fragmented in nature in comparison with large energy infrastructure projects such as power plants [44]. Project aggregation expedites EE financing, as bundling small and medium-size projects into a larger build-up reduce the overall risk and is more appealing to investors.

The Assign Tool creates the ideal circumstances to create links between primary entities that are involved in the procedure of bond issuance. Based on the "Proposal for an EU Green Bond Standard" [45] published in June 2020 by the EU Technical Expert Group on Sustainable Finance, the Assign Tool supports Green Bond issuers to be compatible with the EU Green Bonds Standard by providing all necessary functionalities and information.

The third and final financing method covered by the Assign Tool is the EE auctions. The EE auctions is a policy instrument aiming to achieve energy savings at highly attractive prices and avoiding deadweight effects associated with financial support [46]. The procedure resembles the renewable energy auctions already implemented in a number of countries. Lessons learned and previous experience of EE bidding and auctions in Switzerland have proved that tendering could possibly help to save $26 \%$ of public funds as compared to more traditional subsidise programmes [47].

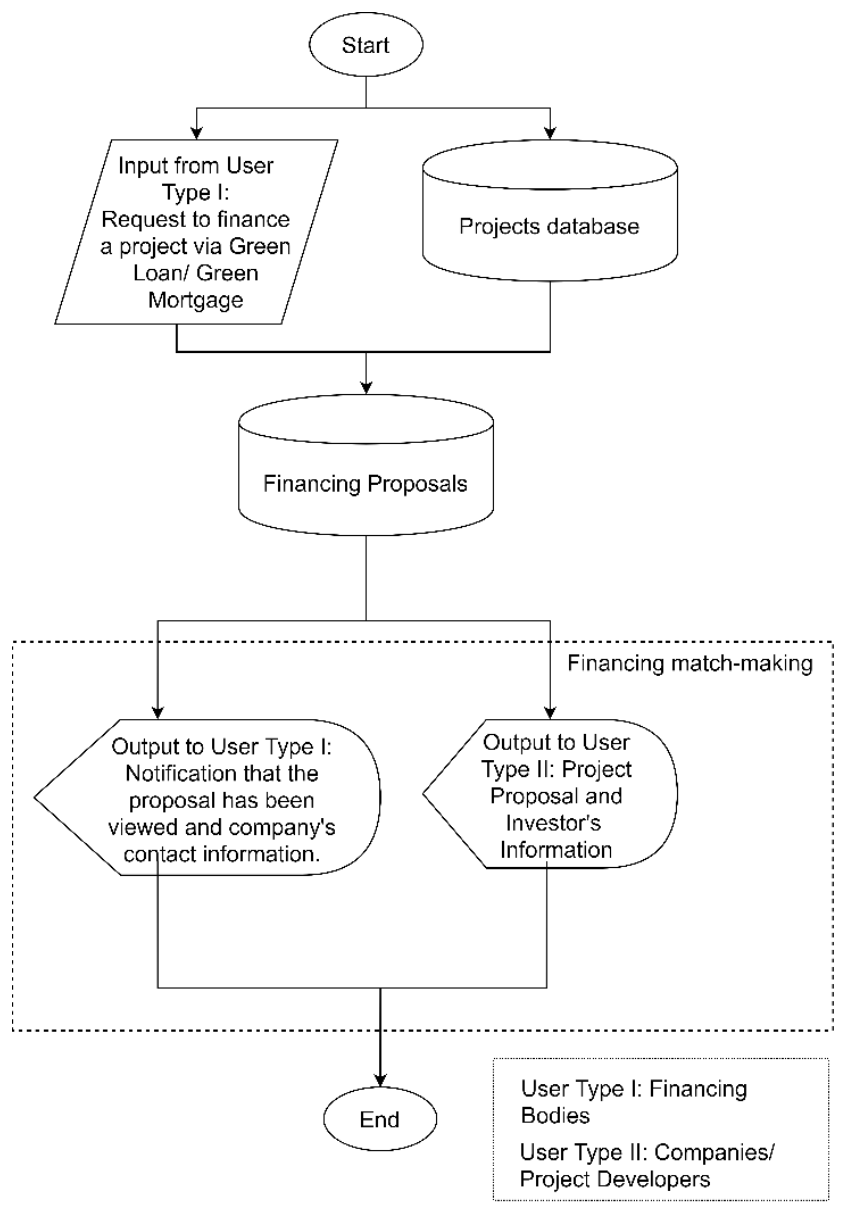

Figure 6: Assign Tool flowchart

The Assign Tool supports the publication of EE auctions in the web-based Tool, enabling interested key actors to get informed about the available auctions. In addition, with the support of the database of projects, followed by the respective information about each project characteristic, stakeholders can filter projects and identify the ones that perfectly match the parameters of the auction. As well, the creation of a printable portfolio of projects is obtainable, and the contact details of each company or project developer are accessible so as to proceed to further actions.

The Triple-A Tools are accessible through the Triple-A Standardised Toolbox platform (https://aaa-h2020.eu/tools), which was implemented in a user-friendly environment, rendering the whole benchmarking procedure flexible and easy to follow, while also offering a communication canal between project developers and financing bodies through flexible options such as green loans and green bonds and energy efficiency auctions.

\section{Conclusions}

It is widely accepted that many investments in EE are well below the required level to meet the established long-term targets, both in economic and energy savings levels. The present manuscript introduces both an integrated methodology to facilitate the financing of energy efficiency projects, as well as a fully- 
featured Web-based Tool, namely the Triple-A Standardised Tools, that incarnates that methodology.

The Triple-A Standardised Tools aspire to set the way for identifying and financing Triple-A investments, based on a solid methodological procedure that takes into consideration many different aspects of the examined investment. The Triple-A Tools are designed with an integrated process, constituting them orientated towards different types of stakeholders in EE financing.

In other words, the developed Tools facilitate project developers to compare and label their projects in a standardised way through the Assess \& Agree Tools, while also providing easy access to financiers, bankers, and investors to finance bankable green projects through the Assign Tool. The Triple-A Standardised Tools have been practically presented to project developers and investors, receiving positive feedback and raising interest in their functionalities through targeted stakeholder consultation activities.

The methodology described in the present paper facilitates EE financing in a practical way, differentiating from existing methodologies, by providing integrated standardized procedures. Also, the methodology:

- Offers a concrete typology of sectors and project types, risk categories, KPIs, benchmarking, and financing Tools widely accepted and known by stakeholders and key actors that do business in the EE sector.

- Incorporate state-of-the-art elements of sustainable financing, such as the EU Taxonomy and the UN's Sustainable Development Goals,

- Ensures interoperability with similar databases and Tools, providing an integrated experience and standardisation to the users.

- Supports innovative financing methods, which are still in the rollout stage but are expected to change the scenery of EE financing, such as the EE auctions.

The Tools developed based on the described methodology provide an integrated approach in a variety of aspects of EE financing:

- the Assess Tool addresses the need for evaluation of the risks and maturity of the examined EE investment ideas along with their EU Taxonomy compliance.

- the Agree Tool provides a solid classification mechanism for the projects that successfully pass the Assess Tool, identifying the remarkable project as the Triple-A ones. Finally,

- the Assign Tool supports the matchmaking of the potential investments with state-of-the-art green financing schemes and creates a community of EE stakeholders (Companies, Project Developers, Investors, Financing Bodies).

The Triple-A Tools provide a one-stop-shop approach to connect project developers with investors, by assessing the maturity and the EU Taxonomy compliance of potential EE projects, while benchmarking them in a standardised way. The respective tools have been already used and tested by stakeholders within the consultation activities of the H2020 Triple-A project [48]. Valuable feedback has been provided and considered and updates have been realised in the Web-based Benchmarking Tool.
In addition, in order to confirm that the developed Tools provide added value to energy efficiency professionals, respective questions have been added to the stakeholder consultation questionnaires and the 53\% have replied that they find the TripleA Web-based benchmarking Tool useful to their profession.

Furthermore, engineering and energy efficiency companies have demonstrated interest in learning more about the Tools and their functionalities, while the Tools' developing team was asked to make a live presentation in the Corporate Social Responsibility School 2021 [49] in July 2021. The Tools will also be demonstrated in the Regional Workshop organised by the TripleA project. In the events mentioned above participate green and sustainable financing investors, engineering companies, project developers that develop energy efficiency projects and policymakers.

Until August 2021, 627 users have visited the Triple-A Tools online platform, while almost 120 stakeholders have been signed up. In addition, 113 projects have been inserted into the Tools in order to be benchmarked and connected with financing methods. Furthermore, the Triple-A Tools have reached 336 participants in the Triple-A events (workshops and Capacity Building Webinars), 72 participants in 59 bilateral meetings and 17 meetings with the Triple-A Advisory Board Members and 198 replies in the respective questionnaires.

\section{Conflict of Interest}

The authors declare no conflict of interest.

\section{Acknowledgement}

The current paper was primarily based on the research conducted within the framework of the EU Horizon 2020 project "Triple-A: Enhancing at an Early Stage the Investment Value Chain of Energy Efficiency Projects” (grant 846569, https://aaa-h2020.eu) aiming to assist financial institutions and project developers increase their deployment of capital in EE, making investments more transparent predictable and attractive. The contents of the paper are the sole responsibility of its authors and do not necessarily reflect the views of the EC.

\section{References}

[1] A. Papapostolou, F.D. Mexis, E. Sarmas, C. Karakosta, J. Psarras, "Webbased Application for Screening Energy Efficiency Investments: A MCDA Approach," 11th International Conference on Information, Intelligence, Systems and Applications, IISA 2020, 2020, doi:10.1109/IISA50023.2020.9284403.

[2] International Energy Agency (IEA), Net Zero by 2050, Paris, 2021.

[3] Council of Europe Development Bank, Energy Poverty in Europe: How energy efficiency and Renewables can help, 2019.

[4] OECD/IEA, Energy Efficiency 2018: Analysis and outlooks to 2040, 2018.

[5] M. Andrei, P. Thollander, I. Pierre, B. Gindroz, P. Rohdin, “Decarbonization of industry: Guidelines towards a harmonized energy efficiency policy program impact evaluation methodology,” Energy Reports, 7, 1385-1395, 2021, doi:10.1016/J.EGYR.2021.02.067.

[6] A. Papapostolou, C. Karakosta, K.-A. Kourti, H. Doukas, J. Psarras, "Supporting Europe's Energy Policy Towards a Decarbonised Energy System: A Comparative Assessment,” Sustainability, 11(15), 4010, 2019, doi:10.3390/su11154010.

[7] Efficiency Financial Institutions Group (EEFIG), Energy efficiency - the first fuel for the EU economy, 2014.

[8] A.B. Jaffe, R.N. Stavins, “The energy-efficiency gap,” Energy Policy1, 22(10), 804-810, 944.

[9] Horizon H2020 Triple-A project, Updated Web-Based Database on Energy Efficiency Financing and Supporting, , Deliverable 3.5, 2021.

[10] C. Karakosta, A. Papapostolou, Transformation Pathways towards a Clean, 
Secure and Efficient European Energy System: A MCDA Approach, Nova Science Publishers, Inc., 2019.

[11] Financing Energy Efficiency | EEFIG Underwriting Toolkit, May 2021.

[12] H. Doukas, "On the appraisal of 'Triple-A' energy efficiency investments," Energy Sources, Part B: Economics, Planning, and Policy, 13(7), 320-327, 2018, doi:10.1080/15567249.2018.1494763.

[13] T. Fawcett, G. Killip, "Re-thinking energy efficiency in European policy: Practitioners' use of 'multiple benefits' arguments," Journal of Cleaner Production, 210, 1171-1179, 2019, doi:10.1016/J.JCLEPRO.2018.11.026.

[14] C. Karakosta, K. Papapostolou, G. Vasileiou, J. Psarras, Financial Schemes for Energy Efficiency Projects: Lessons Learnt from In-Country Demonstrations, Academic Press, 2020.

[15] T. Tsoutsos, S. Tournaki, E. Farmaki, P. Sonvilla, P. Lensing, J. Bartnicki, A. Cobos, M. Biscan, "Benchmarking Framework to Encourage Energy Efficiency Investments in South Europe. The Trust EPC South Approach," Procedia Environmental Sciences, 38, 413-419, 2017, doi:10.1016/j.proenv.2017.03.125.

[16] N. Carbonara, R. Pellegrino, "Public-private partnerships for energy efficiency projects: A win-win model to choose the energy performance contracting structure,” Journal of Cleaner Production, 170, 1064-1075, 2018, doi:10.1016/j.jclepro.2017.09.151.

[17] LAUNCH H2020 | Sustainable Energy Assets in Europe, May 2021.

[18] RenOnBill | About, May 2021.

[19] The Project - EEnvest, May 2021.

[20] E2DRIVER, May 2021.

[21] X-tendo Toolbox, May 2021.

[22] C. Karakosta, A. Papapostolou, Linking Stakeholder Engagement to Multiple Future Policies in the European Energy Sector, 383-392, 2020, doi:10.4018/978-1-7998-1196-1.ch022.

[23] A. Ishizaka, P. Nemery, Multi-Criteria Decision Analysis: Methods and Software, Wiley, West Sussex, 2013.

[24] C. Karakosta, A. Papapostolou, J. Psarras, Concrete Steps towards the Promotion of Renewable Energy Deployment in an Effort to Tackle Climate Change, Nova Science Pub Inc, 2016.

[25] F.D. Mexis, K. Touloumis, A. Papapostolou, C. Karakosta, Deliverable 4.2, Final Triple-A Standardised Tools, Triple-A Project: Enhancing at an Early Stage the Investment Value Chain of Energy Efficiency Projects funded by European Union's Horizon 2020 Grant Agreement No 846569, Athens, 2021.

[26] Austrian Energy Agency, LED Street Lighting Procurement \& Design Guidelines, developed for "Premium Light Pro" Project, funded by European Union's Horizon 2020, Grant Agreement No 695931; Road lighting - Part 5: Energy performance indicators, CSN EN 13201-5, 2015, 2017.

[27] T. Loureiro, M. Gil, R. Desmaris, A. Andaloro, C. Karakosta, S. Plesser, "De-Risking Energy Efficiency Investments through Innovation," Proceedings, 65(1), 3, 2020, doi:10.3390/proceedings2020065003.

[28] Triple-A Final Report on Risks of Energy Efficiency Financing and Mitigation Strategies Typology, Athens, 2020.

[29] F. José, S. Greco, M. Ehrgott, Multiple Criteria Decision Analysis: State of the Art Surveys, Springer Nature, 2006.

[30] B. Roy, J.R. Figueira, J. Almeida-Dias, "Discriminating thresholds as a tool to cope with imperfect knowledge in multiple criteria decision aiding: Theoretical results and practical issues,” Omega, 43, 9-20, 2014, doi:10.1016/j.omega.2013.05.003.

[31] W. Yu, Aide multicritère à la décision dans le cadre de la problématique du tri: concepts, méthodes et applications, Diss. Université Paris IX-Dauphine, 1992.

[32] V. Mousseau, R. Slowinski, P. Zielniewicz, ELECTRE TRI 2.0 a Methodological Guide and User's Manual, Laboratoire d'Analyse et de Modélisation de Systèmes pour l'Aide à la Décision (LAMSADE), Paris, 1999.

[33] E. Mills, "Risk transfer via energy-savings insurance,” Energy Policy, 31(3), 273-281, 2003, doi:10.1016/S0301-4215(02)00040-X.

[34] L. Wang, J. juan Peng, J. qiang Wang, “A multi-criteria decision-making framework for risk ranking of energy performance contracting project under picture fuzzy environment," Journal of Cleaner Production, 191, 105-118, 2018, doi:10.1016/j.jclepro.2018.04.169.

[35] Industrial Energy Accelerator (2020): Energy Efficiency Risk Management - A Report for Financial Intermediaries in Brazil. Report prepared by adelphi (Germany) and SITAWI (Brazil) under the UNIDO lead IEA initiative. January 2020.

[36] T. Pettinger, Factors affecting investment, Economics Help, 2019.

[37] U.S. Environmental Protection Agency, "Understanding Cost-Effectiveness of Energy Efficiency Programs,” 2008.

[38] EBF, Sustainable Finance.

[39] Bankers Almanac, Standard \& Poor’s Definitions, 2018.

www.astesj.com
[40] United Nations, SDG Indicators, Jul. 2021.

[41] Energy Efficiency Financial Institutions Groups (EFFIG), De-risking Energy Efficiency Platform, Apr. 2020.

[42] D. Kahlenborn, C. Annica, I. Georgiev, F. Eisinger, D. Hogg, Defining 'green' in the context of green finance, Brussels, Belgium, 2017.

[43] Internatioanl Capital Market Association (ICMA), Green Bond Principles, May 2020.

[44] Aggregation and bundling of loans for Energy Efficiency - the holy grail for the European Investment Bank: An opportunity for Housing Federations? | Build Up, Dec. 2020.

[45] Technical Expert Group on Sustainable Finance, "Teg Report Proposal for an Eu Green Bond Standard,” (June), 1-79, 2019.

[46] P. Radgen, K. Bisang, I. Koenig, "Competitive tenders for energy efficiency - lessons learnt in Switzerland," in ECEEE INDUSTRIAL SUMMER STUDY PROCEEDINGS, 81-89, 2016.

[47] Swiss Office for energy, Energy efficiency bidding and auctions: Ten years of experience in Switzerland, 2019.

[48] H2020 Triple-A Project, Aug. 2021.

[49] CSR School - Corporate Sustainability \& Responsibility, Aug. 2021. 